\title{
Construção e resgate do saber sobre a agroecologia através de metodologias de intervenção no processo pedagógico
}

\section{Construction and rescue of knowledge about agroecology through intervention methodologies in the educational process}

\author{
Jéssica Oliveira de Souza ${ }^{1}$; Cleberton Correia Santos ${ }^{2}$
}

\begin{abstract}
Resumo: Na busca de um desenvolvimento sustentável, a Agroecologia é uma ciência que articular todos os recursos presentes no ambiente. Porém, muitos ainda desconhecem a mesma, sendo de suma importância sua difusão através de concepções pedagógicas. Desta forma, objetivou-se com este trabalho articular o diálogo de saberes e práticas com estudantes do ensino médio sobre a temática "sustentabilidade e desenvolvimento local". O trabalho foi realizado com alunos de escola pública (Escola Estadual Professora Eufrosina Pinto) por acadêmicos do curso de Tecnologia em Agroecologia da Universidade Estadual de Mato Grosso do Sul (UEMS)/Unidade Universitária de Glória de Dourados. As metodologias utilizadas foram baseadas nas concepções pedagógicas piagetianas (Jean Piaget) norteadas pelo construtivismo e fundamentos teóricos, e freirianas (Paulo Freire), aprimorados a partir da educação popular emancipadora. Os relatos foram anotados, seguido das observações dos participantes. A maioria dos alunos tem conhecimento e percepção significativa sobre os temas relacionados a Agroecologia, sustentabilidade e desenvolvimento local. A utilização das ferramentas pedagógicas Freirianas e Piagetianas foram de suma importância na articulação entre os eixos abordados, sendo metodologias participativas de alta relevância no processo de intervenção.
\end{abstract}

Palavras-chaves: Concepções pedagógicas, desenvolvimento sustentável, observação participante.

Abstract: In pursuit of sustainable development, Agroecology is a science to articulate all the resources in the environment. But many are still unaware of the same, which is extremely important dissemination through pedagogical concepts. Thus, the aim of this study was to articulate the dialogue of knowledge and practices with high school students on the theme "sustainability and local development." The work was carried out with public school students (State School Professor Eufrosina Pinto) by students of the course of Technology in Agroecology at the State University of Mato Grosso do Sul (UEMS) / University Unit of Glória de Dourados. The methodologies used were based on Piaget pedagogical concepts (Jean Piaget) guided by constructivism and theoretical foundations, and Freirian (Paulo Freire), improved from the popular emancipatory education. The reports were noted, followed by participant observation. Most students have knowledge and significant insight into the issues of Agroecology, sustainability and local development. The use of teaching tools Freirian and Piaget were of paramount importance in linking the topics axle, participatory methodologies of high relevance in the intervention process.

Key words: Pedagogical concepts, sustainable development, participant observation.

\footnotetext{
* Autor para correspondência

Recebido para publicação em 12/01/2016; aprovado em 20/05/2016

${ }^{1}$ Estudante do Curso de Licenciatura em Educação do Campo, Universidade Federal da Grande Dourados, Dourados - MS, Jessica_ospasqual@ hotmail.com;

${ }^{2}$ Doutorando em Agronomia - Produção Vegetal, Universidade Federal da Grande Dourados, Dourados - MS, cleber_frs@yahoo.com.br
} 


\section{INTRODUÇÃO}

No decorrer dos anos a agricultura tem apresentado constantes mudanças em seu quadro. A modernização da agricultura privilegiou somente o aumento de produtividade agrícola como parâmetro para avaliar sua eficiência, desconsiderando o agricultor e o meio ambiente como partes do mesmo processo de desenvolvimento, gerando diversos problemas sociais e ambientais (ASSIS, 2002).

Assim conforme Assis (2002) surgiu movimentos de agricultura alternativos ao atualmente predominante, baseados em princípios agroecológicos, e caracterizados por diferentes correntes.

Segundo Capra (1996) a atual crise econômica, social e ambiental da humanidade é essencialmente uma crise de percepção.

$\mathrm{O}$ uso de metodologias participativas, valorizando potencialidades locais e resgatando a auto-estima das pessoas, pode ser importante ferramenta para construção de capital social e empoderamento de pessoas historicamente excluídas das decisões políticas (VIONE, 2002).

Como estratégia para difusão da agroecologia, vê-se a oportunidade de propagação dessa ciência por meio de concepções ligadas ao modelo de visãode Piaget e Freire. Segundo Monteiro (2006), em Piaget a reconstrução de experiências permite a tradução das relações práticas próprias do nível sensório - motor, em relações simbólicas mentalmente representadas.

Como ressalta Monteiro (2006) a reconstrução e a ressignificação de experiências ocorrem pela interação entre significantes e significados, conduzindo à estruturação da dimensão formal do conhecimento pela abstração reflexiva e tradução do significado por diferentes significantes, como a imagem mental, a linguagem oral, a linguagem escrita, o desenho, entre outros.

Conforme pondera Paulo Freire (1970), educação é sempre um processo humano, portanto, ela é fundamentada na transmissão ou na geração de valores. Para ele, não existe educação fora da sociedade humana, sendo assim sua proposta é essencialmente uma pedagogia humanística voltada para as condições humanas, que deve considerar o mundo no qual homens e mulheres estão inseridos.

Assim, objetivou-se com este trabalho articular o diálogo de saberes e práticas com estudantes sobre as temáticas "Agroecologia, sustentabilidade e desenvolvimento local" por meio de metodologias de intervenção pedagógica.

\section{MATERIAL E MÉTODOS}

O trabalho foi realizado com alunos da Escola Estadual Professora Eufrosina Pinto de diferentes níveis por acadêmicos do curso de Tecnologia em Agroecologia da Universidade Estadual de Mato Grosso do Sul (UEMS)/Unidade Universitária de Glória de Dourados, estes sendo124 estudantes matriculados no ensino fundamental e 19 estudantes do nível médio. A Escola está localizada no município de Glória de Dourados $\left(22^{\circ} 22^{\prime} 03,3^{\prime \prime} \mathrm{S}\right.$ e $53^{\circ} 55^{\prime} 03,8^{\prime}$ ' W, $420 \mathrm{~m}$ ), na região da Grande Dourados, Mato Grosso do Sul, Brasil.

As metodologias utilizadas foram baseadas nas concepções pedagógicas piagetianas (Jean Piaget) norteadas pelo construtivismo e fundamentos teóricos, e freirianas
(Paulo Freire), aprimorados a partir da educação popular emancipadora.

Para realização de uma análise prévia e para que em outro momento possa realizadas outras atividades foi utilizado um questionário com duas questões abertas a um grupo de professoras: 1) O que vocês entendem por agroecologia?; 2) Qual a relevância das atividades realizadas no ensino?., além da participação dos alunos. O processo de avaliação final das atividades foi realizado com auxilio da auto-avaliação e discussão com as pessoas envolvidas.

Os relatos foram gravados, e transcritos, também foi utilizada a técnica da observação dos participantes.

\section{RESULTADOS E DISCUSSÃO}

Em todas as turmas buscou-se resgatar as experiências dos alunos, fazendo que as atividades pedagógicas fossem norteadas por estes pontos de comunicação, trazendo a realidade deles para as atividades intervencionistas. Assim o interventor tem o papel de "dar força e jeito para que esses grupos populares transformem de fato o dia de amanhã" (FREIRE. in FREIRE; NOGUEIRA, 1989, p. 21).

Um cuidado para com todas as turmas foi à abordagem pela oralidade, tendo em vista que a mesma pode passar um aspecto negativo, podendo haver uma sobreposição da fala do interventor sobre o conhecimento popular. Tendo em vista que deve ser valorizado o conhecimento popular dos alunos em junção com o conhecimento cientifico do interventor, promovendo o dialogo dos saberes. Assim:
"se o discurso do acadêmico soa alto e dominante sobre a fala popular, esse discurso congela-se em conceito, congela a consciência, faz com que esta adormeça no interior de frases feitas. Desaparece a ênfase na luta, entendida como curiosidade interrogadora e crítica da ordem. Permanecerão somente pacotes de frases feitas". (FREIRE. in FREIRE; NOGUEIRA, 1989 p. 30-31).

Então a participação do agente extensionista interventor deve ser de forma participativa para com os alunos, onde a partir da mesma, possa contribuir no processo de desenvolvimento e sensibilização da sustentabilidade através de abordagens para aprendizagem coletiva. De acordo com Gadotti (2012) a educação popular comunitária, trabalhando com a categoria "produção" (associada à categoria "conscientização+organização") buscam formas de "aprender produzindo", onde a realidade da própria comunidade é o ponto de partida em busca de desenvolvimento.

A proposta inicial foi se realizar uma breve apresentação abordando o tema "Agroecologia e Desenvolvimento Sustentável" com auxilio de data show. Porém as turmas do período matutino se mostraram altamente participativas, assim optou-se de não se utilizar da apresentação e apenas um diálogo com os mesmos.

Os alunos do $8^{\circ}$ ano $\mathrm{A}$, comentaram que já haviam ouvido falar sobre os alimentos orgânicos em rádio e televisão e o relato foi:

[...] Não sabemos muito bem o que é agroecologia, mas sabemos que é ter um ambiente sustentável e sem uso de 
agrotóxicos $[\ldots]$

Tanto que uma das alunas relata que se avô praticava agricultura orgânica. Estes se mostraram altamente empenhados e participativos diante do conteúdo abordado em diálogo. A turma do $8^{\circ} \mathrm{B}$ do período matutino não sabiam e não conheciam muito sobre os alimentos orgânicos, agroecologia ou sustentabilidade, porém começaram a mostrar grande interesse por trabalhar com atividades na horta presente na escola, pois eles não trabalham nas aulas de ciências em virtude de carência de projetos pelos professores.

Nas turmas do período vespertino, foi necessário utilizar o auxilio quando necessário de apresentação em slides, em virtude que a maioria das turmas não participava de forma efetiva. Apenas quando eram realizadas algumas perguntas sobre determinados pontos da Agroecologia e da sustentabilidade e de experiências. Poucos alunos se mostraram participativos diante asabordagens.

As turmas de $8^{\circ}$ ano $\mathrm{C}$ e $\mathrm{D}$, não participam, eram mais fechados e vergonhosos. Quando dialogado sobre saída para atividades fora da escola, passaram a impressão de apenas sair para não terem aula, foram poucos os alunos que se interessaram pelos assuntos abordados.

Este processo de comunicação entre os sujeitos é de alta significância no processo de abordagem e intervenção, baseando na ação comunicativa. Esse controle reduz as capacidades de ação comunicativa entre as pessoas como ressalta também Habermas $(1990 ; 1992)$ que com sua "teoria da ação comunicativa" que busca reabilitar o mundo da vida com vistas a superar a alienação humana. Assim, compreendendo seus interesses e necessidades.

A turma do $9^{\circ}$ ano D é constituída por $50 \%$ dos alunos são de áreas urbanas, e os demais da área rural, um dos alunos que reside em área rural relata em seu relato:

[...] Tudo que a gente planta lá é para consumo nosso e é feito de forma natura [...]A gente lá em casa usa os estercos do nosso gado, porque ajuda pra diminuir nossos gastos e ainda pra gente comer [...]

Freire em seus trabalhos relata que a educação emancipadora é baseada no processo de transformação social, assim analisando diferentes dimensões da realidade dos alunos e ampliação e respeito à relação sujeito-sujeito.A maioria dos alunos do $9^{\circ}$ ano $\mathrm{C}$ reside na zona rural e, seus familiares aplicam agrotóxicos e não utilizam de equipamentos de proteção individual e também realizam práticas de desmatamento, tanto que um dos alunos apresentou o seguinte relato:

[...] O patrão do meu pai pediu pra gente arrancar umas árvores e nós contratamos mais gente, arrancamos a noite e enterramos [...].

E os demais começaram a indagar sobre a fiscalização do IBAMA e sobre os aspectos ilegais, apresentando os seguintes discursos:

[...] Onde está o IBAMA nessas horas? [...] Eles não ganham pra isso? [...].

Os estudantes acreditam que em grande maioria das vezes estes órgãos fiscalizadores recebem dinheiro para não cumprirem com seus deveres. Após este período de questionamentos, uma aluna relata:

\section{[...] O uso de agrotóxicos é bom porque ajuda a} combater pragas e as coisas que dão nas plantas [...].

Diante desta afirmação apresentada, foi abordado sobre técnicas sustentáveis e manejos que contribuem no controle de doenças e pragas em sistemas agrícolas, este não estava no planejamento. $\mathrm{O}$ assunto foi o qual a turma mais se interessou, realizando diversos questionamentos através dos seguintes relatos:

\section{[...] Como conseguir? [...] Como aplicar? [...] E depois} que as pragas morrem, o que acontece? [...].

Assim, foram explanados e discutidos sobre todas as dúvidas e em seguida os alunos eles relatam que preferem o alimento orgânico.

A turma de $3^{\circ}$ ano do ensino médio $\mathrm{B}$ no começo do diálogo estabelecido mostrou-se pouco participativa. Ao decorrer da abordagem dos conteúdos, os alunos foram se mostrando mais interativos e participativos. Quando abordado sobre o tema do "Setor Sucroalcooleiro" na região de Mato Grosso do Sul, um dos alunos apresenta o seguinte relato:

[...] Tem seus prós e contras, como toda atividade, pelo lado bom gera emprego e pelo lado ruim causa degradação [...]. discursos:

Outro aluno fez as seguintes indagações através dos

[...] Vocês acham que com essa produção, vocês irão conseguir saciar a fome de 7 milhões de pessoas? [...] Percebe-se que o setor de vocês ainda é fraco diante dos outros diversos setores da economia, vocês acham que vão conseguir vencer esta batalha?[...].

Pode se perceber o alto grau de conhecimento dos alunos em relação à Agroecologia, e outros diversos setores.

Foi realizada uma contextualização abordando a produção de alimentos e uso dos recursos naturais renováveis ao longo dos anos. O aluno que fez o segundo relato ainda fez a seguinte afirmação:

[...] Quero ser daqueles que quero mandar nos soldados, trabalhar pouco e ganhar muito [...].

Diante deste discurso, pode-se verificar que o pensamento do estudante é o oposto aos grandes pilares da sustentabilidade, onde se busca uma sociedade igualitária, com atividade economicamente viável e ecologicamente correta.

Para Freire, a educação é concebida como processo de emancipação e transformação do mundo, em que o papel do educador não é o de convencer o educando, mas de vencer com ele (MDA, 2010). Assim "Ninguém liberta ninguém, ninguém se liberta sozinho: os homens se libertam em comunhão" (FREIRE, 2000: P52).

$\mathrm{Na}$ avaliação também foram considerados discursos das três professoras que estavam presentes com as turmas em seus respectivos horários de aulas. O questionamento realizado 
para as mesmas foi em relação à agroecologia e sua relação com a sociedade e sobre a realização das atividades com os alunos.

Os relatos foram:

(1) [...] É importante que haja essa conscientização com os alunos ainda jovens, pré-adolescentes, porque é preciso ter conhecimento sobre os produtos tóxicos, orgânicos e economia sustentável. É de pequeno que deve começar a mudar a idéia sobre a ecologia que está sendo muito afetada pelo homem [...]

(2) [...] A agroecologia é a oportunidade de sermos pessoas melhores, para fazermos um mundo melhor [...]

(3) [...] A agroecologia é uma ciência que tem como objeto de estudo o setor agro inter-relacionado com o meio ambiente e seria uma produção de gêneros alimentícios associados à preservação do meio ambiente (natureza) [...]

Todas as professoras pediram para realização de mais atividades e que se pudéssemos desenvolver um projeto para trabalhar com a escola na área de horticultura orgânica.

\section{CONCLUSÕES}

A maioria dos alunos tem conhecimento e percepção significativa sobre as temas de Agroecologia, sustentabilidade e desenvolvimento local. A utilização das ferramentas pedagógicas Freirianas e Piagetianas foram de suma importância na articulação entre os eixos abordados, sendo metodologias participativas de alta relevância no processo de intervenção.

\section{REFERÊNCIAS BIBLIOGRÁFICAS}

ASSIS, R. U. Agroecologia no Brasil: análise do processo de difusão e perspectivas $f$ Renato Unhares de Assis. Campinas, SP: [s.n.]. Tese (Doutorado) - Universidade Estadual de Campinas.Instituto de Economia. 2002.

BRASIL. Ministério do Desenvolvimento Agrário. Fundamentos teóricos, orientações e procedimentos metodológicos para construção de uma pedagogia de ATER. Brasília: MDA/SFA, 2010. 45p.

CAPRA, F. A teia da vida. São Paulo, Editora Cultrix , pp. 23 a 25, 42. 1996.

FREIRE, P. Pedagogia do Oprimido. Rio de Janeiro: Paz e Terra, 1970.

FREIRE, P. \& NOGUEIRA, A. Que fazer: teoria e prática em educação popular. Rio de Janeiro: Vozes, 1989.

Paulo Freire e o nacionalismo desenvolvimentista. São Paulo: Graal, 2000.

GADOTTI, M. Educação popular, educação social, educação comunitária: conceitos e práticas diversas, cimentadas por uma causa comum. Revista Diálogos: pesquisa em extensão universitária. In: VI Congresso Internacional de Pedagogia Social: domínio epistemológico. Brasília, v. 18, n. 3, dez. 2012.

HABERMAS, J. "Soberania popular como procedimento". Novos Estudos CEBRAP, n.26, março, 1990, p.100-113.

"Further reflections on the public sphere". In: Calhoun, Craig (Ed.). Habermas and the public sphere. Cambridge; London: MIT Press, 1992, p.421-461.

MONTEIRO, M. T. L. A psicopedagogia da integração social por coordenação de ações, por reconstrução e ressignificação de experiências. Apostila (Mestrado em Educação) Faculdade de Educação, Universidade Católica de Brasília, 2006.

PADILHA, A. C. M. Gestão ambiental de resíduos da produção na Perdigão Agroindustrial. XLIII CONGRESSO DA SOBER. Sociedade Brasileira de Economia e Sociologia Rural. Ribeirão Preto, 2005.

VIONE, G. F. Metodologias participativas na construção de planos de desenvolvimento local. Monografia (Especialização) Instituto de Ciências Humanas e Sociais Pós-Graduação em Desenvolvimento, Agricultura e Sociedade UFRRJ, 2002. 